\title{
Research article: Coexistence relationship between non-governmental organizations and public order in China
}

\author{
Qiong Li ${ }^{1,2}$ \\ ${ }^{1}$ School of Sociology and Public Management, East China University of Science and Technology, ShangHai, China \\ ${ }^{2}$ Department of Sociology, Purdue University, Indiana, USA
}

\section{Email address: \\ liqiong102@126.com}

\section{To cite this article:}

Qiong Li. Research Article: Coexistence Relationship between Non-Governmental Organizations and Public Order in China. Humanities and Social Sciences. Vol. 2, No. 6, 2014, pp. 157-172. doi: 10.11648/j.hss.20140206.14

\begin{abstract}
In the progress of modernization, it is still a project to be further explored how we can establish an effective and rational public order. Non-governmental organizations are the interactive vehicles that form the part and whole system. Through an analysis of the co-existing relationship between non-governmental and governmental organizations, this study intends to examine the functions that the non-governmental organizations perform in the structuring the social order. Accordingly, we will systemize, institutionalize and structurize the corporate system. Only on the basis of the inscape of the regional social order can we find a pattern that will lead to a generally harmonious one. In this way we can get our ideas into shape how to develop the present Chinese society harmoniously.
\end{abstract}

Keywords: Non-Governmental Organizations, Public Order, Coexistence

In the society with a Chinese planned economy, government performs various social functions in different ways. With the deepening of the reform and opening-up, all these efforts in performing social functions seemed to fall flat. The market is unwilling to get involved, while government is incapable of the management; as a result, we must return social functions to the third sector so as to achieve coordinated development. Non-governmental organizations are the major players in returning social functions to the civil sector, and we cannot achieve such a goal without the development of non-governmental organizations, without constructing the coexistence relations between non-governmental organizations and government.The primary question is not freedom, but the construction of lawful public order. It is very obvious that legal and reasonable public order is not only the premise of the existence of social functions, it is also the value pursuit in social development.

\section{Research Approach}

With the in-depth research on non-governmental organizations, two major research perspectives begin to take shape, that is, the power perspective and the legal perspective. In the 1970's, with the vigorous development of non-governmental organizations, there was a tremendous transformation in social management environment, which requires the government to set off from social autonomy implied in public administration, take as a connecting node the coexistence relations emerging from social management practices, and consciously construct and bring about a new service-oriented administration pattern. Consequently, the research on the relations between non-governmental organizations and the government must adjust itself to the transformation of the management environment so as to realize the perspective transfer concerning the relations of the two.

\subsection{Power Perspective}

Since both government (state) and non-governmental organizations are involved subjects in the research on the relations between non-governmental organizations and government, and that the two are derived from different historical periods, we should start from the later generated non-governmental organizations when we make researches on this topic.

As introduced above, the prosperity of modern non-governmental organizations does not come from nowhere. Ancient civil charities are their predecessor. Nevertheless, modern non-governmental organizations in western countries 
have grown out of the civil society, quite contrary to the traditional charities in the pre-civil society. Therefore, the relationship between non-governmental organizations and government from the power perspective should be based on the state-society separation in modern times. Government's altitude towards social self-organization systems. Government (state) is a tool for social governance and services, and "a power stemming from the society, posed by itself as above the society, and gradually separated from the society". Government (state) is supposed to reconcile conflicts and keep them within the social order. For government, viewing the relationship with non-governmental organizations from the power perspective is the most typical starting point to maintain the social order. Capable of providing public goods and services, non-governmental organizations are even more powerful than government in some areas. This is why government always intends to repel and restrict all self-organization systems in the society. The development of charities in modern times, as introduced in the previous two chapters, can clearly reflect such restrictions on non-governmental organizations.

The concepts of "statism" and "marketism" had been on the upswing during the state-society separation in modern times. People believed that public welfare was a natural duty of the state, which was beyond the market and should be kept away from non-governmental organizations. For example, it was clearly stated in the Regulations for the Use of Charity Funds published by the U.K in 1601, that charities were "a function shared by the private and public sectors", and that the state was the general owner of charity funds, i.e. the "general founder of funds". During the establishment and integration of the capitalist society, the state, out of its needs for maintaining and solidifying the legality, "had changed social welfare into a war between the church and the state, as well as a war between manufacturers and laborers". In this way, the tradition of church and private charities, which had been passed down from the Middle Ages, suffered a serious hit, and secular states gradually became the perfect monopolist of charities. Theories like "end of charities" and "failure of charities" even emerged in the western society between the end of the $19^{\text {th }}$ century and the beginning of the $20^{\text {th }}$ century. Even in the $1950 \mathrm{~s}$, the Nathan Committee, the public welfare authority of the U.K still believed this: "One of the most tragic failures in our history is the efforts of these philanthropists...It has been proved by the history that those civilian efforts were doomed. Today, statutory services from the state - either new services or old ones - can provide personal welfare from cradle to grave...What else can philanthropists do?"

The suppression on non-governmental organizations is mainly decided by the historical process of the society. The formation of national states in modern times is also the process of how an agricultural society was gradually transformed into an industry society. As the society transformed, the governance model of the human society was also changing. The governance model of an agricultural society is a dominated social governance model, or "dominated administration", while the social governance model of an industry society is a managed social government model, or "managed administration". During the transformation from the dominated administration model to the managed administration model, the state will change its ways and approaches for social governance. Yet in either of the social governance models, "political domination is always based on its performance of some social function, and cannot proceed until it performs such social function". During the rise of modern countries, driven by the need for legal domination, the rising bourgeoisie had to grow stronger by seeking social welfare from the state. However, against the context where constitutional states had yet to be formed, and the rule of law was still in progress, the governments preferred to take over the power heritage from the agricultural social governance model. This explains why the governments leveraged their administrative power to repel and suppress any rivals to the extent possible. It was not until the 1970s that the western welfare states gave up their basic stance of evaluating non-governmental organizations with the "tinted glasses" of power.

Government's repulsions and restrictions on non-governmental organizations are directed by and based on its power perspective towards the latter. On the other side of this relationship is the high reliance of non-governmental organizations on political legitimacy and other resources from government. However, as put forth by Dahl, an American political scientist, "the allocation of social resources directly decides the boundary of social governance by government". The "scattered-to-radiated" resource distribution in the industrial society is totally different from the "accumulated-to-centralized" resource distribution in the agricultural society. In an agricultural society, the government can monopolize the resources, dominate the resource distribution through its administrative power, and force the society to submit to the resource allocation model dominated by the power relationship. In an industrial society, however, the scattered resource distribution overturns the government's power-based domination of resource allocation, and there are objectively many non-governmental resource allocation centers in the society, which fundamentally breaks the government-monopolized resource allocation in the agricultural social governance model, and puts an end to the perfect monopoly of resource allocation by the government. Therefore, there truly exists a growing environment for non-governmental organizations in the industrial society. A few modern countries may still carry out the harshest suppressions on non-governmental organizations, but this can at most change their forms and territory of existence, rather than virtually cut off their source of existence.

\subsection{Legal Perspective}

The way of resource distribution in the industrial society makes it possible for non-governmental organizations to gradually escape the powerful control of government. Correspondingly, under the managed administration of the industrial society, the growth of non-governmental organizations is regulated by government through a lot of legal 
policy tools. From the temporal perspective, it was since the widespread outbreak of the welfare state crisis, the development crisis and the environmental crisis in the 1970s that governments have started to build their relationship with non-governmental organizations towards a legal one. Under various social pressures, the governments carried out a variety of administrative reforms to separate the so-called "steering" and "paddling" functions. Meanwhile, the regulation was generally getting looser, with supports and funds given to a considerable number of non-governmental organizations for social services. At this moment, the governments begun to revalue the role and functions of non-governmental organizations, and tried to influence them on the basis of legal norms and guidance so as to build a "cooperative-complementary" relationship. In this way, the functions of non-governmental organizations were acknowledged by the governments. They grew more quickly than ever, which even led to the worldwide "associational revolution".

The evolution from the bare power relationship to the softer legal relationship indicates that the social governance model has been softened and improved. Substantially, the transition from the power perspective to the legal perspective is a further step of the "movement from status to contract" of the capitalist revolution. Under the managed administration model, all social issues are handled by the way of thinking of instrumental rationality, and the relationship between non-governmental organizations and government is also included into such a thinking framework. The direct significance is that the prosperity of non-governmental organizations in the legal framework indicates a contractual trust relationship of both parties after non-governmental organizations are given the legal legitimacy, and such relationship inevitably comes from the social governance by managed administration. Since modern times, legal construction has been a magic weapon of government to keep the market economy growing on the right track. While satisfying the need of the market economy for fair order, governments have gradually changed the power-based dominated administration to the legal-based managed administration. Contract is the essence of law, and "law exists to protect the right for the freedom of contracting and the right for strict fulfillment of freely-made commitments". Therefore, the basic way of social governance by managed administration is to build the social life under the spirit of contract and the principle of legality. Government's efforts to build the relationship with non-governmental organizations from the legal perspective actually manifest how managed administration shapes the social life and reconciles the conflicts and contradictions in social interests under the spirit of contract. By replying on the spirit of contract, government has brought together people from all classes, ranks and interest groups so as to unite the entire industrial society in form.

However, the contract-based trust relationship is established to avoid trade risks, and its effects completely rely on law and power. Both the status relationship and contractual relationship are external human relationships, so the contractual trust relationship derived therefrom is a secondary cooperative relationship instead of a primary one. Therefore, the contractual trust relationship targets utilitarian trading, strongly featuring formalism and instrumentalism. "Contract is indeed a wall among people, linking their interests and keeping their hearts apart." It "turns the accidental trust crisis among people into an unavoidable one, excluding the trust among people from all aspects of the society, and making the trust crisis even more serious."

The process of building this contractual trust relationship reflects the "select-control" intention of government for non-governmental organizations. Non-governmental organizations are valued by government not because government is willing to give up their domination of social governance, but because it has to retreat and compromise in face of "ineffectiveness" and social pressures. Compared with the repulsions and restrictions from the power perspective, the legal framework accepted by government is a door opened by it for non-governmental organizations' participation in social governance. To pass through the door, however, non-governmental organizations have to verify their administrative legitimacy according to law. The "administrative legitimacy" of non-governmental organizations "usually goes through the process of enabling and acquisition", following the logic that "I acknowledge you (the organization) because you comply with me (or the value and regulations I represent), which means the reason for your existence is lawful, and thus your social activities will not be questioned". A non-governmental organization not complying with the value and regulations represented by the government will not obtain the administrative legitimacy enabled by the government, even if its service functions are acknowledged by the society. Therefore, the verification of administrative legitimacy is in fact the requirement of the "selection-standardization" mechanism for non-governmental organizations. Having been selected and standardized, non-governmental organizations can then be assumed "lawful" and permitted to provide public services as a supplement to government. Such a contractual trust relationship can only be an equal relationship in form, rather than conceal the actual inequality between the two parties. Under the managed administration model, government is entitled to interpret the laws and make judgments. It "as the ultimate origin of law, is superior to law and may not be bound by law"; it is "the highest judge for its self-interests that interfere with others' interests". This violates the basic maxim of justice: "anyone shall not be the appropriate judge for the cases in which its self-interests interfere with others' interests".

Therefore, the relationship between non-governmental organizations and government built from the legal perspective is in fact a power relationship veiled by formal equality, as well as a contractual trust relationship dominated by such power relationship. This exactly verifies Habermas' comments on capitalist legal countries: "A reasonable administrative management system and an independent judicial system are the organizational conditions of capitalist 
legal countries." Social governance dominated by the legal perspective will inevitably lead to the paradox of governance: Firstly, non-governmental organizations are a public service tool originated from the society, but they have to seek for administrative legitimacy from government, another public service tool, instead of directly from the service target (the society). This seems to be a detour. Secondly, with the legal framework established, non-governmental organizations have been divided into organizations "inside the system" and organizations "outside the system". Organizations "inside the system" may grow into "quasi-governmental organizations" which have deviated from their nature; meanwhile, a large number of non-governmental organizations "outside the system", operating beyond the boundary of governmental regulations, are facing the dilemma of legalization although they might be able to serve the purpose of social services.

This paradox can be widely found in modern countries, showing that managed administration, in which social governance counts on the contractual trust relationship, is still one of the control-oriented social governance models. Similar to dominated administration, social public power in such a model is still the alienated social public power which does not take services as the core value and ultimate goal for existence. However, the growth of non-governmental organizations in the managed administration model has led to the division and recombination of the social structure, representing the creation and development of service ethnical values in the social governance system.

\subsection{Coexistence Perspective}

The coexistence perspective has gradually emerged as public order management took shape. On one hand, the market economy empowers government with the function of public order management and makes it the subject of public order management; on the other hand, as the market economy grows, various kinds of autonomous and interim organizations are summoned from the society to perform this function as well. Consequently, public order management has the practical characteristic of dual subjects.

In this dual-subject model, non-governmental organizations, as an autonomous way of social groups, are in nature a non-profit self-organization phenomenon, and a wide path for public will and interests. As the market economy grows and the idea of diversified interests deepens, there will be more non-governmental organizations emerging in the society. All these organizations are a positive power driving the civil society to be more rational. By cultivating the subject and autonomy consciousnesses among their members, these organizations will inspire the enthusiasm of social members in directly participating in social public affairs. Implying freedom, equality and autonomy and with service as the ultimate value, these organizations tend to build self-organization systems different from those on a power or legal basis. Non-governmental organizations are at the same time a medium between government and the society. Before the rise of non-governmental organizations, government and the society used to dialogue through representative institutions.
After non-governmental organizations sprung up, government has found new channels for such dialogue. The diversity of non-governmental organizations decides diversified dialogue channels between government and the society. As a result, government freed itself from its entrustment-agency relationship with representative institutions and its responsibility for the latter. Instead, it dialogues with the society in more direct and diversified ways, directly provides services to the society and is responsible for the society. In this way, government and non-governmental organizations are equal social service bodies in the social governance structure, with the public service spirit and the concepts of equality, cooperation and coexistence deeply rooted in the whole social governance system.

After giving it a careful thought, we may find that the rise of non-governmental organizations implies its echoic resilience to the public power that used to be held by government. Such resilience is not only embodied by non-governmental organizations competing with government for the provision of public services, but also embodied by the ethnical spirits they represent (self-service, cooperation and equality) penetrating into the government system. More importantly, this resilience will be solidified into an objective governance mechanism, driving government to more voluntarily decentralize its power to the society and local areas, and to provide social autonomous organizations with more opportunities and space. Both providers of public services, they need to cooperate in social governance practices to fulfill their own missions. As a result, the previous repulsion and restriction relationship and contractual trust relationship between the two parties are replaced by the coexistence relationship. Disciplines and rules in the government system that are based on the order-obedience relationship, after government learns from non-governmental organizations about the service spirit, will finally become ethical. Following this process, governmental organizations will take coexistence as the core value for existence. Therefore, social autonomy in public management includes the objective mechanism that can help create the concept of coexistence. This indicates that government will have to rebuild its relationship with non-governmental organizations from the perspective of coexistence.

The relationship built from the coexistence perspective is a trust relationship on a truly equal basis. It is not an absolute negation of the power and legal perspectives, but an inheritance of the reasonable essences of its two predecessors guided by the coexistence value. On one hand, the core value of coexistence does not absolutely exclude fairness and efficiency. The coexistence-guided objective mechanism in the new social governance system determines the relationship among the social governance subjects will be built on the basis of an equal, tolerant and cooperative ethnical relationship. This coexistence relationship is also a competitive and complementary relationship, with each party having its strong points. And all the public management subjects share the ultimate purpose of serving the society. Therefore, from the ethnical perspective, this coexistence orientation will surpass fairness, efficiency or other values in the previous social 
governance models, and endow them with new teleological meanings. On the other hand, the efficiency and order shaped under the power and legal perspectives can be sublated under the influence of the coexistence spirit of public management. The contractual trust relationship under the legal perspective, particularly, is indeed a generator and catalyst for formal justice. Directed by the core value of coexistence, the morality implied by contract will be more fully manifested in the relationship of public management subjects, and grow into a strong power rebuilding government with the coexistence spirit. Therefore, to echo with the transition to the former social governance model, the establishment of this new social governance model may be called a movement "from contract to coexistence".

To sum up, there are three totally different perspectives regarding the building of the relationship between non-governmental organizations and government: power perspective, legal perspective and coexistence perspective. Transition among the three perspectives echoes with the changes in the governance environment of the human society. The power perspective represents the dominated administration model, and its transition to the legal perspective reflects the decline of the agricultural social governance model and the rise of the managed administration model of the industrial society. With drawbacks of the current managed administration model and the arrival of the public management era, we can get a clue of a service administration model growing in the managed administration model. This new social governance model is in nature a social service and coexistence system on an equal basis.

Under this new social existence system, a reasonable relationship between non-governmental organizations and government is to be built in the direction of the coexistence spirit, which leads to methodological breakthroughs of the perspectives towards this relationship. Realizing this coexistence relationship and actively building an equal coexistence relationship become a rational consciousness of government for public administration. Consequently, government needs to fully understand the social essence of non-governmental organizations, and to build a coexistence relationship with non-governmental organization with a more equal and active altitude. This trust relationship will also be turned into social capital, bonding government and the society in harmony. Under such a trust relationship, government will shift its focus from the means of power to the purpose of power, and will work together with non-governmental organizations on public interest practices.

\section{Roles in Public Supply}

Consumers, producers, and arrangers/providers are the three primary participants on the public goods supply chain. Firstly, consumers, who directly obtain or receive public goods, may be individuals, all individuals in a special geographic area, government agencies, or non-governmental organizations. Secondly, public goods producers, who directly organize production or directly provide services for consumers, may be government agencies, voluntary non-governmental organizations, private enterprises, NPOs, or sometimes even consumers. Thirdly, public goods providers, who assign producers to consumers, assign consumers to producers, or select service producers, are usually - but not necessarily - government agencies. Government, non-governmental organizations or consumers may all play the role of public goods providers.

Therefore, government can be both a producer and an arranger. But it is not the only choice. Non-governmental organizations can also be a provider and producer of public goods. What is the relationship between these two kinds of public organizations as providers of public goods and services? What is this relationship supposed to be? Is it a cooperative or conflicting relationship?

\subsection{Cooperation}

As analyzed in the "Introduction" chapter, theoretical descriptions of the cooperation between non-governmental organizations and government are primarily corporatism on a macroscopic level. In the corporatist system, there are a limited number of non-competitive interest groups with mandatory or semi-mandatory membership. With their own specific privileges, these interest groups work with government on policy making, instruct their members to accept negotiated agreements, and be liable for policy implementation. Therefore, corporatism is a macro-institutional arrangement for the cooperation between non-governmental organizations and government, focusing on institutional channels for organizations' communication and interest articulation with government. On a microscopic level, the cooperation relationship between government agencies and non-governmental organizations as well as enterprises is summarized by new public administration as "a strategic partnership between the public and private sectors". Each category has its own strength, which is summarized by David Osborne and Ted Gaebler in the famous book Reinventing Government: How the Entrepreneurial Spirit Is Transforming the Public Sector, as follows:

Table 1. Strengths and weaknesses of three types of organizations in public goods provision

\begin{tabular}{llccc}
\hline & \multicolumn{3}{c}{ Tasks Most Suitable for Each Type of Organizations } \\
& (E=Effective & I=Ineffective & D=Depending on the environment) \\
\hline & Governmental organizations & Market organizations & Non-governmental organizations \\
\hline Most suitable for governmental organizations & & & \\
Policy management & $\mathrm{E}$ & $\mathrm{I}$ & $\mathrm{D}$ \\
Management execution & $\mathrm{E}$ & $\mathrm{I}$ & $\mathrm{E}$ \\
Fair play & $\mathrm{E}$ & $\mathrm{I}$ & $\mathrm{D}$ \\
Preventing discrimination & $\mathrm{E}$ & $\mathrm{D}$ & $\mathrm{D}$ \\
\hline
\end{tabular}




\begin{tabular}{llll}
\hline \multicolumn{4}{c}{ Tasks Most Suitable for Each Type of Organizations } \\
(E=Effective & I=Ineffective & D=Depending on the environment) & \\
\hline & Governmental organizations & Market organizations & Non-governmental organizations \\
\hline Preventing exploitation & $\mathrm{E}$ & $\mathrm{I}$ & $\mathrm{E}$ \\
Improving social cohesion & $\mathrm{E}$ & $\mathrm{I}$ & $\mathrm{E}$ \\
Most suitable for market organizations & & $\mathrm{E}$ & $\mathrm{D}$ \\
Economic tasks & $\mathrm{I}$ & $\mathrm{E}$ & $\mathrm{D}$ \\
Investment tasks & $\mathrm{I}$ & $\mathrm{E}$ & $\mathrm{I}$ \\
Making profits & $\mathrm{I}$ & $\mathrm{E}$ & $\mathrm{D}$ \\
Improving self-sufficiency & $\mathrm{I}$ & $\mathrm{I}$ & $\mathrm{E}$ \\
Most suitable for non-governmental organizations & & $\mathrm{I}$ & $\mathrm{E}$ \\
Social tasks & $\mathrm{D}$ & $\mathrm{I}$ & $\mathrm{E}$ \\
Tasks to be done voluntarily & $\mathrm{D}$ & $\mathrm{D}$ & $\mathrm{E}$ \\
Tasks making small profits & $\mathrm{D}$ & $\mathrm{I}$ & $\mathrm{E}$ \\
Improving the sense of responsibility of individuals & $\mathrm{I}$ & $\mathrm{I}$ & $\mathrm{E}$ \\
Enhancing community & $\mathrm{D}$ & $\mathrm{I}$ \\
Improving the responsibility for the welfare of others & $\mathrm{D}$ & \\
\hline
\end{tabular}

It can be seen from Table 1 that both non-governmental organizations and government have their strengths and weaknesses as providers of public goods and services for the society. Each has its own characteristics and abilities, which makes it possible for them to cooperate. There are mainly two ways of cooperation: cooperation under co-existence and cooperation under the division of labor. Cooperation under co-existence means government and non-governmental organizations complementing or competing with each other for public services for the same targets in some common areas. For example, government and non-governmental organizations both provide social relief, health care, education and other public goods, where they play the similar roles and are complementary to each other. Government provides policy-making and public services on a macroscopic level, whereas non-governmental organizations provide public services for communities, groups or individuals on a microscopic level. In this case, they might be competitors. Cooperation under the division of labor is a way of cooperation where non-governmental organizations and government have different duties for provision of some public goods and services, with different organizations playing different roles on different links of public goods, and all the organizations working together to provide the society with public goods and services under the division of labor and cooperation. Where a non-governmental organization signs a contract with the government for its provision of social services for a community, the government is the arranger, the non-governmental organization is the producer, and the community members are consumers.

As the modern society grows, the cooperation between non-governmental organizations and government is becoming more and more important. "People will work harder to unite the strengths of interim organizations, families, individual volunteers and communities, promoted by government from time to time. A partnership will thus be established to boost public welfare to a higher level."

\subsection{Conflicts}

Non-governmental organizations and government are both providers of public goods and services, but this doesn't mean they cooperate without conflicts. There are two types of conflicts: those for public interests and those for group interests.

Though both provide public goods and services, government has a diversity of public targets that conflict with each other, while non-governmental organizations have simpler and more centralized ones. As a result, some simple target of non-governmental organizations may conflict with a number of target sequences of government. For example, educational non-governmental organizations consider education as the most important issue at present. In the government's opinion, except education, there are many other public targets such as social fairness, national defense, foreign affairs, economic efficiency, public utilities, etc., and it is not feasible for the government to make policies and grants totally as per non-governmental organization's wishes. This will lead to some tension between the two parties based on different public targets, and even conflicts in some areas.

When one party violates public interest, the other party takes an opposite position and acts. This is another conflict for public interests. In many developed countries, there are non-governmental organizations supervising the government's behaviors and fighting against government corruption. In Korea, for example, there are organizations supervising national policy makers, as well as anti-corruption or anti-corruption related non-governmental organizations, branches of international non-governmental organizations, and institutes of universities. When there are violations of public interests by government officials or policies, these organizations will protest by parades, comments or media.

Conflicts for group interests are the conflicts between the partial interests of non-governmental organizations and the wider public interests of government. "People usually believe the real conflicts in the modern political history are between individuals and the state. In fact they are between the state and social organizations and groups." Non-governmental organizations are voluntary unions of citizens, based on beliefs and values, or common interests. In China, social groups based on beliefs and values are public interest groups, and those based on common interests are mutual interest groups, which mainly protect the interests of their members, a 
narrow form of public interests. Therefore, conflicts between the group interests and the government's public interests are unavoidable. Some may change into interest groups, lobbying and bargaining with the government so as to protect the group interests. Non-governmental organization's protection of their own interests will most probably affect the social public interests. Such negative effects should therefore be avoided or reduced through transparency of group affairs, news supervision, etc.

\subsection{Separation}

There is another possible relationship between non-governmental organizations and government: they do not cooperate or conflict, but are independent from each other in a large sense. There are surely few cases that can demonstrate such relationship, including the legendary Shangri-la, a typical example for the absolute separation of government and some social organizations (villages). In the modern society, however, organizations can rarely exist beyond the influence of government - government has its social influence everywhere due to the industrial rationality of the modern society and the bureaucratic structure of governmental organizations. Therefore, there is a basic suppressed premise before we talk about the possible separation of non-governmental organizations and government in the modern society: non-governmental organizations comply with the basic legal systems established by government, on the basis of which they carry out autonomous governance, free from arbitrary interference by government. Examples include some interest groups and clansmen associations, which limit their activities within a certain scope, and are not obviously involved in the government's implementation of public policies. Relevant studies also show that non-governmental organizations are among numerous autonomous organizations in the world. They make rules once established, and request the members to observe the rules to protect their common public interests. For example, through a worldwide investigation on the solutions for common-pool resources, Ostrom believes social self-organization is the best solution for common-pool resources, in which the related parties establish associations and other non-governmental organizations, make rules for each other, and request all to observe the rules, so as to protect a sustainable utilization of common-pool resources. In a relative sense, many non-governmental organizations are separated from government in the modern society - they and the government are two different kinds of organizations, conducting activities in different areas.

Though both provide public goods and services, non-governmental organizations and government work under different mechanisms for such provision, which results in their distinctive difference in ability, resource and flexibility. The relationship between non-governmental organizations and government as providers of public goods and services is complex, which is summarized in this paper as cooperation, conflicts and separation. Obviously, this summarization cannot include all the possibilities, and their real relationship is much more complex than what has been summarized. In conclusion, non-governmental organizations and government are two different public goods provision mechanisms. It is irresponsible to draw a quick conclusion that one is superior to the other. It is most important to make clear of their characteristics, and find out the most effective type of organization according to the characteristics of public goods and services.

\section{Strong-Weak Association}

\subsection{Government Control: A Necessary Way to Obtain Social Order}

In terms of state existence and development, the significance of social order is a true proposition without any need of proof. However, access to social order has different approaches, one of which is comprehensive and strict social control by the government using the majority of social resources monopolized by it. This approach, whether in history or practice, has always been considered as the most effective by the power holders. Many scholars call this approach the structural morphology of "strong nation and weak society". In fact, it is not a very appropriate term. In a sense, the very reason why this approach is chosen is because the state is weak and does not have universal legitimacy. In addition, this supply approach of social order brings endless negative influence to the whole nation while it temporarily intensifies the social order. Specifically, it inhibits the vigor of social development, resulting in the trade-off of social development and social order, which will further arouse disorder and unrest of the whole society. In other words, this approach is characterized by the government's exclusion of all social forces. There are two ways of exclusion, one is to close the channel for the citizens to enter politics, and the other is to cancel the citizen's requirements of economic participation. This shows alienation of public authority for the citizens, which will inevitably affect the formulation of public policies by the government. Therefore, the unrestricted bureaucracy only needs to be accountable to itself, and the government can implement of the self-aggrandizement policy at its own will.

Indeed, the public power controlled by the government can be a coercive power to obtain social order. With the development of politics, today the strict design of public power operating mechanism has already made the compelling force of public power pervasive. It can be deep into every corner of society so as to conduct effective control of the society. However, the compelling power of public power is actually based on violence or threats of violence, such kind of compelling power is not the basis of true legitimacy of government. The power object is forced to obey through compelling force; such obedience is rather because of the fear of consequence than their own needs. However, human beings are senior animals characterized by various desires, diverse emotions, and thinking and judge abilities, which determines human beings can not endure this forced relationship for a long time. If the public power subject cannot, at the very least, meet the minimum requirements of part of the social members, 
the public power object will definitely feel mentally frustrated, and continue to accumulate rebellious grievance for the public power subject. Thus this power relationship cannot maintain long-term recognition.

With the deepening of China's reform process, state power has withdrawn and is withdrawing from the economic and social fields orderly. Through the reform of economic system, the government's economic function has been separated and continues to be separated for the enterprises to shoulder. In the process of social reform, the government's social function inevitably needs to be separated gradually for the non-governmental organizations to share. In terms of the function transferred from the government, the prerequisite for the non-governmental organizations to share is the non-governmental organizations have to be mature and competent. However, the non-governmental organizations in China are relatively weak, which needs the government to consciously nurture the non-governmental organizations, and needs to encourage the whole society to pay attention to the healthy development of the non-governmental organizations and establish a good symbiotic relationship with the non-governmental organizations. The symbiotic consequence between the non-governmental organizations and the government is not only beneficial to the growth of the non-governmental organizations, but will accelerate the transformation of government functions.

\subsection{Specific Role of Non-Governmental Organizations in Overcome the Failure of State Intervention}

\subsubsection{Guarantee the Legitimacy of State Intervention Right}

As a politics term, the legitimacy of public power is not consistent with the existing legal norms, the legitimacy of public power should be perceived from the intrinsic relationship between the subject and object of the internal public power. Aristotle wrote in his Politics that "if a form of government wants to achieve the purpose of long-term stability, it must be able to make all the people of the various parts of the state participate and embrace the willing to maintain its existence and continuation." Lipset stated that "legitimacy shows the ability of political system to make people produce and insist the idea that the existing political system is the most suitable system of the society." The above point of view is exactly the understanding of the legitimacy of public power based on the intrinsic relationship between the subject and object of the internal public power. In the final sense, the realization of public power does not primarily rely on power subject, but whether the power object is willing to obey. This is because the legitimacy of public power represents the justification of the power subject in possessing and applying power recognized by the power object. Habermas holds that "legitimacy means there are sound grounds for certain political orders required to be recognized as correct and impartial existence. A legal order should be acknowledged. Legitimacy means the value of certain acknowledged political orders - this definition emphasizes that legitimacy is controvertible validity claims, and the stability of ruling order also relies on it actually being acknowledged."

Legitimacy means the public's recognition and obedience of political power. This is the desire of any government, because "even the strongest will never be strong enough to master for good, unless he transforms his strength to power, obedience to liability." However, "strength does not constitute power", "we only have the responsibility to obey legal power". Government intervention with legitimate foundation is recognized and supported by people; the effective intervention of any government owes to legitimate support. If there are problems concerning legitimacy, government intervention is bound to be out of order.

Study shows that the public in modern society have two core requirements for the self-certified legitimacy of public power - performance and democracy. Performance means when public power provides public service for social members, it has to comply with the principle of rational calculation: maximum output with minimum input; democracy means the existence and operation of public power must try its utmost or be conductive to realize the ideal of public self-management. Similarly, the legitimacy of state intervention also needs to prove through these two approaches.

Performance is the basis of legitimacy of state intervention, which requires the government to establish and regulate an efficient system of economic intervention, also requires the government to achieve more benefits with less input when providing such intervention. Performance standard is consistent with the principle to guide people to maximize the benefits in various activities, "the priority of human need must be the ultimate foundation to judge the legitimacy of public policies." In addition, we all want a smallest scale of government with lest expenses to provide most public products and services. Vicious expansion of government scale and expenses, low performance and incapacity to provide public desired products and services often indicates the loss of legitimacy of state intervention.

In such era as "democracy, as political value, has been widely acknowledged, and the implementation of democracy has become a worldwide trend", democracy has become the important and firm foundation for the legitimacy of state intervention. Democratic principle of state intervention is mainly reflected in the reorganization of social members' right to participate in social management, namely intervention participation right.

As an important element involved in governance, non-governmental organizations is beyond the mode of thinking of dichotomy between government and market, it "deals with the failure of market and (or) state coordination by means of governance mechanism", seeks to achieve optimal allocation of social resources through governance, so as to create relatively good economic performance. In addition to the government, due to their characteristics of nonprofit, public welfare, organization and voluntariness, etc., non-governmental organizations stand out from the social organizations, becoming ideal partner and preferred successor for the government. They can also provide public products, with even better supply performance. The social management 
process which is able to maximize the public interest is good governance. Thereafter, the governance with non-governmental organizations involved is response to the inefficient government intervention; it is consistence with the public's appeal for efficient management of public affairs.

The integration of non-governmental organizations into governance is confirmation of principal-agent relationship in democracy; it is the requirement to regularize the principal-agent relationship, and the suspect of the legitimacy of supply of public goods monopolized by the government, which reflects the pursuit direction of returning society to people. The integration of non-governmental organizations into governance reflects the requirement to pursue formal rationality of performance; it also reflects the requirement to pursue substantive rationality of democratic way of life. Both requirements co-exist in governance in a relatively harmonious way. The requirements of democratization, such as multi-center, decentralization, regularization of principal-agent practice, public-private partnership, etc. have become the approaches and tools to pursue efficient performance of public products supply from the perspective of governance. Performance with formal rationality relies on democracy with substantive rationality, while formal rationality expedites substantive rationality. The integration of non-governmental organizations into governance meets both the two core requirements of legitimacy of public power: performance and democracy. Under the governance model with non-governmental organizations involved, the foundation of legitimacy of public power is thus able to be laid so that the public power aiming at good governance can obtain high reorganization of legitimacy.

\subsubsection{Offset the Failure of Government Supplies of Public Goods}

The study made by Ostrom on police services and public pond resources such as water resources shows the seemingly disorderly public service field actually has rules to follow. That is to say public goods are not exactly the same; different types of public goods are able to and should be provided through different manners.

Non-governmental organizations do not aim for profit; the funders who provide funding to create or expand the operation scale of non-governmental organizations do not expect to obtain rewards on investment, nor to recoup their investment. The non-governmental organizations generally aim at macro-social benefit, instead of micro-economic benefit. This feature of non-governmental organizations determines that they not only play a complementary role for the government in the public goods field, but, to some extent, have the unique advantage to effectively overcome the failure of government function in public goods field.

Non-governmental organizations do not take the maximization of corporate profit as their goal, but are lead by certain mission, which is nonprofit, and represents a concept with strong sense of public welfare, so as to enable them to become organizations with strongest sense of mission. As a free organization for public voluntary participation, non-governmental organizations are different from hierarchical power principle operated by the government; they are diverse, flexible, equal, and participatory organizations. Thus, they enjoy the advantage of even lower cost and high efficiency compared with the government when supplying public goods. The operating mechanism of non-governmental organizations can effectively combine market mechanism and self-organized social forces. The solution of double failure government failure and market failure in field of public goods is organically combine the effectiveness of both market mechanism and government role; non-governmental organizations can make good combination of the two parts using a variety of ways.

\subsubsection{Reduce the Cost of State Intervention}

Cost can be produced due to state intervention, which is the price for achieving efficiency after the market is intervened. In the process of state intervention, it is uneconomic if intervention cost exceeds intervention benefits, and it is unnecessary because of its inconsistence with the principle that market economy aims at efficiency. An important component of government intervention cost is maintenance of its huge institutions and personnel growth costs. The government should take on the functions of intervention in market economic activities, including organization of public goods supply, maintenance of social and economic order, etc., thus relevant agencies and personnel are needed to perform this function. Adolf Wagner stated early in the 19th century: the government, by nature, has a natural tendency to expand. Particularly the public departments have an inherent tendency to expand in respects of quantity and importance during their intervention in social and economic activities, it is called by the western economists "Wagner law of rising public expenditure". This inherent government expansion more fits the society's growing demand for public goods, which may easily lead to the expansion and intensification of government intervention function, and the growth of its institutions and personnel. As a result, the increasing size of the budget and fiscal deficits evolves to the expensive costs for government intervention.

Under the governance doctrine with modern non-governmental organizations involved, governmental organizations still act as a very important role in the whole society, especially in respects of legitimate use of violence, determination of the direction of major public resource allocation, protection of fundamental rights of citizens, realization of fair value, etc, the government will continue to plays a role without a parallel by any other organization. Nevertheless, it is no longer the only core of power in implementation of social management function. This means the non-governmental organizations, civic self-organizations and other organizations will work together with the government to assume the responsibilities to manage public affairs and supply public service, the rights of these organizations will also be recognized by the society and the citizens. The internal logic of this transformation is civic and social self-organizations will become a trend, individual 
responsibility of citizens as well as the consequence individuals decide to bear will grow to be the major principles in the process of social selection, and multiple competitions are constantly pulled into the process of supply and production of public goods and services.

As the major carrier for the transfer of government powers and functions, non-governmental organizations are conductive to the transformation of government functions and the successful simplification of government agencies. In the past, government's public power surpassed social power, some powers are originally belong to public powers, should be performed by the government, which inevitably needs the appropriate executive departments, resulting in insufficient development of social self-management authority, the expansion of government agencies, and increasing management and intervention costs. As the government looses its management of micro-economic and social affairs, instead of establishing many micro-economic management departments, the government needs to focus on macro-management, realize a moderate size of a government with a moderate number of officials. The intervention of economy and social affairs should maintain at an appropriate range, the intervention mode of economy should conduct appropriate transformation of administrative management methods, so as to accelerate a simplified government.

\subsubsection{Improve the Efficiency of State Intervention}

Some government intervention is less efficient. Contrary to market mechanism, government intervention, in the first place is characterized by publicity which does not regard direct profits as its goal. In order to compensate for market failure, the government tends to perform direct intervention in the fields of public goods which have large investment, slow and less profits. Such supply is generally characterized by non-price, that is, the government is not allowed to charge directly the suppliers through exchange with clearly marked price. Such fields primarily depend on expenditure to maintain their production and management. It is difficult to calculate the costs, therefore, they are not driven by the direct profit to reduce costs and increase efficiency. Second, government intervention is also classified by monopoly. The government's position of monopoly supplier of "some urgently needed public goods (such as defense, police, fire, and highway)" determines only the government has the function and power to externally intervene and regulate the overall operation of the market. This monopoly lacks competition, which is liable to make the government lose the pursuit of efficiency and benefits. Finally, government intervention is also required to have a high degree of coordination. The organizational system of government regulation is constituted by numerous government departments and agencies, the delineation of authority, coordination, sector perspectives among which affect the operation efficiency of regulation system.

Inefficiency of state intervention often stems from wrong government decisions. Government intervention in social and economic activities is actually process to formulate and implement complex public policies involving many areas.
Right decisions must be based on adequate and reliable information. But this kind of information is produced and transmitted among numerous scattered individuals, making it hard for the government to completely occupy. In addition, the complexity and variability of market economic activities in modern society increase the difficulty of the government's complete control and analysis of information. This situation can easily lead to wrong government decisions, and will inevitably produce irreversible negative effects for the operation of the market economy. The right decision also needs decision makers with high quality, the macro-control by government must rely on correct judgment of market operating conditions, and the formulation of control policies need to take the necessary measures. All these are rather difficult to practice. Even with correct judgment, appropriate selection and collocation of policy tools, the intervention effort is difficult to determine. However, both insufficient and excessive intervention will cause "government failure". The fact is most of the government officials do not have the above quality and capacity to make decisions, which will inevitably affect the efficiency and effect of government intervention.

Independent non-governmental organizations are effective channels for exchange of information and energy between the state and the social members, and interaction intermediary between the state and the society. Non-governmental organizations use various methods to hold activities for social mobilization, integration and expression of interests, cohesiveness of social consensus, etc, forming a universal view incorporating interest demands, ideas, and values orientation. This kind of information entries the decision-making system through certain channels, or instead of entering the decision-making system, widely spreads outside of decision-making system, which is considered as the pressure to affect decisions. The message expressed by these organized activities with aims is important reference for political decision-making; the message expressed by these organizations in the process of policy implementation is feedback in the process of implementation of government policies. These functions of non-governmental organizations guarantee reasonable government decisions, and self-correction in the implementation of policies.

Like the management of governmental organizations, that of the non-governmental organizations is not driven by profits, but relies on the guide of mission or cohesion. Non-governmental organizations obtain external support and contributions by means of mission which is able to reflect social needs, and propaganda, so as to realize internal co-operation. Therefore, the service management methods and experience those non-governmental organizations have obtained - in respects of focus on efficiency and performance are significant reference to the government departments, which can improve the efficiency and quality of supply of public goods. On the other hand, the development and growth of non-governmental organizations intensifies the government's cooperation with non-governmental organizations in the field of public goods, increases different ways and channels for the government to provide public goods, 
and promote the quantity and quality of public goods provided by the government. Compared with government supply of a variety of public services, the supply of specific public goods entrusted to the independent non-governmental organizations by means of funding enjoys three advantages: as independent organizations, the non-governmental organizations can justifiably charge service fee from the public when providing services, so as to reduce the total government cost, and cost allocation; second, non-governmental organizations, as independent organizations, cost less than the government departments, particularly in respect of labor force; third, non-governmental organizations is able to find donation for ideal service accordingly. At the meanwhile, non-governmental organizations have strong economic mechanism to control

\subsubsection{Reduce the Possibility of Non-Just State Intervention}

The justice of government intervention is not inevitable. One of the prerequisites is government intervention should impartially regulate the market operation on behalf of social and public interests. The public-choice school regards government officials as the hypothesis of "economist" motioned by Adam Smith. This may be biased; however, the government in real life is indeed always so noble. It is not rare of the so called "internal effect" during the government organizations' pursuit of internal interest instead of public interest, and corruption of government officials is not less frequent. Such pursuit of "internal effect" by the government will greatly affect the optimal allocation of resources under government intervention. Same as the reason of external effect for market failure, "internal effect" is a major source of government intervention failure.

The existence of non-governmental organizations, as the backbone of civil society, enables the civil society to become a better-organized and stable society. In the civil society, when faced with threat of state political power, the interest-independent social individuals derived from private property rights system will spontaneously organize a variety of political, economic, professional, and other social groups to protect individuals or communities' interest against such threat, so as to maintain social stability and avoid the political and economic upheavals. This function will undoubtedly contribute to organized social order, while one premise of democracy is stable and well-organized society. The performance of social supervision through increase of transparency and social openness is conducive to restricting the generation of restricting corruption and promoting public interests.

\section{Coexistence Strategy Selection}

\subsection{The Necessity and Feasibility of Coexistence between Non-Governmental Organizations and Government}

Unlike in western countries, non-governmental organizations in China are heavily influenced by the government for their each step forward, but are constantly trying to become independent of the government as they expand and grow. Therefore, how to perceive and handle their coexistence relationship becomes a must to handle challenge for both parties.

\subsubsection{Necessity}

As non-governmental organizations and government are complementary and have their own respective advantages, their coexistence can bring these advantages into full play and achieve mutual promotion and development.

Non-government refers to an organization that is independent of the government. In terms of source of funding, these organizations use or mainly use private capital to establish rather than relying on or mainly relying on funds provided by the government; in terms of subordinate relationship, they have their own autonomy and independence rather than a leader-subordinate relationship with the government. Though they are not governmental departments or subordinate to the government, non-governmental organizations can provide public services that the government should but somehow couldn't do or do well in a short time. From this perspective, non-governmental organizations are in fact organizations with similar functions as the government and should coexist with the government. On the other hand, regardless of their willingness, non-governmental organizations have to face the challenge of handling its relationship with the government. Currently, the most prominent problem is that their relationship hasn't been dealt with properly. The following three aspects can demonstrate this problem:

1. "Offside" refers to that the government supervises several activities that should be shouldered by the non-governmental organizations. This is mainly reflected in some industrial associations established during the institutional reform. During the economic system reform, the government transformed some of its subordinate departments into non-governmental organizations in order to separate government from community and government from enterprises, as well as change its functions. These organizations active in certain socioeconomic fields are in fact under the administration of relevant government departments, thereby becoming dependent on the government. In such a relationship, the government often interferes too much or improperly with non-governmental organization's internal affairs and operational activities. This is offside.

2. "Vacancy" refers to that the government gives up some of its functions due to certain reasons. In China, there are still a large number of non-governmental organizations either registered or unregistered with the Department of Industry and Commerce, which receive no supervision from the civil affairs department and the supervising agency. When exercising their functions to nurture non-governmental organizations, the government departments often fail due to lack of specific content and measures. 
3. "Misplacement" refers to that the government assigns non-governmental organizations to deal with activities that should be taken by itself, which results in role misplacement. The problems of government-community and government-enterprises marriages, deep-seated bureaucracy and government undertaking social administrative affairs are still waiting to be solved fundamentally.

The second prominent problem is that the government hasn't found an effective way to nurture and manage non-governmental organizations. In recent years, both central and local governments have attached great importance to the development of non-governmental organizations and issued documents reiterating the importance of "nurturing and supervising simultaneously". But in practice, the government places too much emphasis on supervision and management, rather than nurture and promotion. Even though the government puts great emphasis on supervision, there are still several problems. For example, compared with foreign non-governmental organizations, Chinese non-governmental organizations have obvious disadvantages in terms of preferential policy and financial support. Non-governmental organizations in western countries receive $30 \%$ of their funds from the government, some even reach $45 \%$. However, Chinese government has provided little favorable policy support to these organizations. In recent years, to better manage, standardize non-governmental organizations and bring them into full play, the government announced in succession a series of documents such as Management of the Registration of Social Organizations, Provisional Regulations for the Registration of Private Non-Enterprise Work Units, and Provisional Regulations for the Name Management of Private Non-Enterprise Work Units. Though these regulations have played a positive role in the transformation of non-governmental organizations, on the whole there are still such problems as small number, incompatible and hard to operate. In particular, there are no official, comprehensive and rigorous laws and regulations on how to manage non-governmental organizations, which is quite incompatible for a big country with 136,000 non-governmental organizations and 700,000 private non-enterprise organizations.

For non-governmental organizations, the most important external relationship is the relationship with the government, which can directly affect the long-term development of these organizations as well as steady progression of social economy. Zhao Liqing has divided this relationship into four categories: (1) opposite and distrust; (2) independent of the government; (3) dependent on the government; and (4) cooperative. Obviously, the fourth one is an ideal status for non-governmental and non-profit organizations. Although non-governmental organizations have been emphasizing on missions and goals that differ from the government, as well as their autonomy and independence, both parties are dedicated to promoting the country's economic and political development, which serves as the basis for their coexistence and codevelopment. No matter what kind of organization it is, the government's support and encouragement will provide a favorable environment for its operation. Therefore, to complete its mission, an origination has to get not only permit and acknowledgement from the government, but also diversified resources such as funds, information, technology and facilities. In fact, no organization in any country can develop at its own discretion without any influence from the government.

\subsubsection{Feasibility}

Non-governmental organizations and the government are neither enemy nor friend, they not only compete directly or indirectly, but also cooperate on a regular basis. Their competition is not adversarial, because their purpose is to gain more resources in the public service filed to provide better public goods rather than rebel against the government. Therefore, non-governmental organizations and the government have the coexistence basis to a certain extent.

First, they share the same common value goals: providing high quality public services to all citizens. In this regard, they are consistent and free of conflict. Any monopoly in public service by any party will directly affect the diversification, quality and efficiency of public goods deliveries. Therefore, coexistence will play a very important role in addressing divergences and conflicts rising from the fierce competition between non-governmental organizations and the government.

Second, diversified governance trends of public affairs in the globalization era lay a solid foundation for their coexistence. The government is facing invasions from both upper and lower sides and part of its functions are transforming: in modern society, the government is decentralizing its rights to local governments, intermediaries, society and enterprises, while transforming to supranational organizations or international organizations. This transformation lays the foundation for cooperation between non-governmental organizations and the government who are pursuing the same public goals. After rapid expansion of government agencies and their functions after the Second World War, with significant increase in fiscal expenditure, western governments could hardly provide public services that were recognized by the public due to their inherent monopoly and bureaucracy. In light of credit crisis, financial crisis and management crisis, western governments had to loosen their governance of public service, began to exit certain fields that they put too much effort but still couldn't manage well and actively seek to cooperate with non-governmental organizations. Meanwhile, non-governmental organizations, from the very beginning, had been actively seek to cooperate with the government, took over those fields that the government ignored and exited, and actively responded to the transformation of governance structure of public service.

Third, both parties have their own respective advantages in the public service field. Some scholars have pointed out that resource complementation is the key driver for cooperation between the government and non-governmental organizations. The coexistence might be an effective way to accumulate 
resources and strengths from both sides to solve complicated issues, and improve efficiency to solve issues and innovation. Non-governmental organizations can effectively absorb private capital and provide effective services and governance to consolidate interest requirements of relevant classes, thereby playing their unique role in promoting social welfare and social fairness. While the government is irreplaceable in developing macro public service policies and plans and providing direct or indirect financial support to non-governmental organizations participating in public service governance.

Of course, their coexistence first depends on a modern democratic government which adheres to accommodation, dialogue and cooperation. Because the government has mandatory public rights during the public service governance while non-governmental organizations have no such backing, therefore once conflicts arise, non-governmental organizations can only turn to laws and regulations. Therefore, both parties have to make clear of their respective rights, responsibilities and obligations based on the legal system and laws and regulations to achieve equal cooperation in the public service filed. Meanwhile, non-governmental organizations have to solve the autonomy issue by making clear of their commitment, exploring diversified financial resources, establishing good public foundation, and mastering technology expertise and social management knowledge, to stay independent instead of subordinate to the government.

\subsection{Reference System for their Coexistence}

The coexistence between non-governmental organizations and the government is a relationship with mutual respect and support based on advantages complementation, rather than subordinate to or independent of one another. Both parties need to gradually explore a long-term and stable division cooperation system through cooperation on some short-term specific projects to provide systemic guarantee for their coexistence. In this respect, many governments have established a contractual relationship with non-governmental organizations in recent years, which we can learn and borrow from their experiences.

For example in UK, non-governmental organizations and the government have established an institutionalized cooperation. According to a survey report on non-governmental organizations and through extensive consultation, the central government and non-governmental public welfare organizations reached a cooperative agreement in 1998, local governments and local non-governmental public welfare organizations subsequently reached agreements in succession to provide guidance for government agencies and local governments to establish cooperation with non-governmental organizations when developing and implementing public policies.

These agreements give a guidance framework, recognize the irreplaceable position of non-governmental organizations as the third department, emphasis on their complementation in terms of developing public policies and providing public services, and make clear that the government should provide supports to promote the development of non-governmental organizations in various fields. The key principles of these agreements are as follows:

1. Acknowledge that healthy non-governmental public welfare organizations are an essential part of a democratic society;

2. Independent and other forms of non-governmental organizations serve as the basis for a public welfare society;

3. Both parties have their own respective advantages in developing public policies and offering public services;

4. As they have the same goal, through cooperation, both parties can create more value and improve policy development and service quality;

5. Though they represent different interest groups, both parties need to be comprehensive, objective, open, responsible and honest;

6. Non-governmental public welfare organizations are qualified to participate in election campaigns in order to achieve their goals;

7. The main role of the government is to provide financial support to non-governmental organizations, which is an important element in their relationship;

8. Both parties have recognized the importance of equality of opportunity for everyone, regardless of skin color, age, sex and religious belief.

The cooperation agreement between the UK government and non-governmental public welfare organizations states that the responsibility of the government is to:

1. Promote and facilitate the cooperation agreement among government agencies;

2. Respect the independent of non-governmental organizations;

3. Consult in time when developing public policies; and

4. Guarantee that non-governmental organizations have equal opportunity to receive funds from the government to provide public services.

The responsibility of non-governmental organizations is to:

1. Promote and facilitate the cooperation agreement among non-governmental public welfare organizations;

2. Operate activities through transparent and responsible institutions;

3. Represent different interest groups and tolerate differences; and

4. Provide constructive advice on the development of public policies.

Given the special national conditions in China, especially China is in a period of economic and social transformation, there is no ready-made mode to copy. Therefore, we need to not only learn from the successful experiences of foreign countries, but also carry out specific practice and systemic innovation so as to find a proper coexistence road.

Firstly, the government needs to set up the notion of equality, makes clear that both parties are equal and complementary in the process of society co-governance, further improves the rules and regulations on management of non-governmental organizations, reduces direct 
administrative intervention, defines the responsibility and rights of both parties, acknowledges the autonomy and independence of non-governmental organizations, as well as enhances the self-discipline and social supervision system of non-governmental organizations. The government should release measures on management of non-governmental organizations that can actively provide guidance and nurture rather than pure supervision and control. Secondly, the government should encourage the whole society to focus on non-governmental organizations, provide support for their healthy development, help them enhance capacity building, create a favorable environment, and offer more room for their activities. On one hand, the government should provide more supports in various ways for non-governmental organizations, especially social welfare and public service organizations, to change the situation of financial dependence on international assistance seen in the past. This can not only improve their living and development conditions and enhance their ability to provide public services, but also improve the government's resource utilization rate to effectively coordinate and guide activities of non-governmental organizations from a social development planning perspective. On the other hand, the government should set up effective supporting policies to encourage enterprises and individuals to undertake their social responsibilities and public welfare activities, so as to promote the development of social charity and voluntary undertakings and provide support for their public welfare services. Thirdly, the government should incorporate the cooperation with non-governmental organizations into its reform and reflect and strengthen the cooperation in government agencies and relevant departments. It is believed that some local governments have redefined their roles in the pilot administrative system reform, separating public service enterprises such as hospitals, libraries, culture museums and museums from the government agencies they are subordinated to, and putting under the newly established public service commission, thus freeing and enabling the government agencies to put more energies on industry management and guidance. This solves the problems of public institutions and regulation and management marriage. Therefore, the government should carry out innovations on systemic reform so as to adapt to the changing political, economic and social environment.

Generally speaking, Chinese non-governmental organizations are still at a low level in terms of autonomy, independence and voluntaries, so there are still many problems which hinder them to undertake more public service functions transferred from the government in a short time. The ability of self-construction of non-governmental organizations is critical to the promotion of cooperation, including the ability to manage organizations, operate in accordance with specialization standards, undertake high quality projects, coordinate and expand, develop and innovate as well as deal with unexpected incidents. Non-governmental organizations should develop and implement effective measures to solve these problems with the support of the government and the society. Meanwhile, they need to carefully select, support and guide their cooperation with the government. Majority of non-government public welfare organizations have strong sense of calling, and will definitely play a more important role in driving the society forward as they gradually improve their abilities.

Non-governmental organizations and the government should gradually set up scientific and standardized management measures and an evaluation system on public service programs, to improve cooperation efficiency and effects. Moreover, they should establish a coordination system with respective responsible departments to carry out evaluation on the cooperation on a regular basis. The government, non-governmental organizations and enterprises may convene a forum annually which will serve as a platform for them to dialogue, communicate, summarize experiences and discover problems. It is of great importance for Chinese systemic reform and innovation to enhance the research on interactions among the government, markets and civil society. The cooperation between non-governmental organizations and the government is a symbol of social progress, but there is still a long way to go. A relationship with positive interaction will benefit both of them and promote the development of social public welfare and the construction of a harmonious society.

\subsection{Coexistence Strategies for Non-Governmental Organizations and the Government}

Different arrangements can be applied to the delivery of different public goods based on different levels of exclusivity and competition. To sum up, the coexistence strategies for non-governmental organizations and the government to deliver public goods are as follows:

1. Contract. It refers to that the government and a non-governmental organization sign a contract on public goods and services. Under this arrangement, the government is responsible for ensuring the quantity and quality of the public service program and entrusting the program through competitive bidding to a non-governmental organization. The winning bidder shall offer public goods to the public in accordance with the contract, while the government shall purchase this service through financial allocation, and supervise and evaluate the quality of the service. In this case, the government is the arranger and the non-governmental organization is the direct producer. For some unprofitable public service programs, markets have no enough incentives to undertake these programs, while non-governmental organization is willing to do so as long as the government provides enough funds to sustain its operation. For example, United States Department of Health and Human Services signed a contract with Blue Cross and Blue Shield Association to entrust the latter to undertake the health care service for millions of old people across the country.

2. Franchise. The government rents out office facilities, buildings and land to non-governmental organizations instead of purchasing services through financial 
allocation, to engage in activities that the government allows. Under this arrangement, similar to the first one, the government is the arranger and the non-governmental organization serves as the producer. The major difference between the two arrangements lies in the payment mode to the producer: the government pays to the producer versus consumers pay to the producer. The difference between non-governmental organizations and market profit organizations lies in that the former can provide public goods at much lower price than the market, thereby lowering consumer burden and improving social welfare conditions. Franchising is an effective way to relax market constraints and broaden entry fields.

3. Generally speaking, there are two types of franchises, exclusive franchise and non-exclusive franchise. The government should flexibly adopt an appropriate way based on actual situations. If adopting the exclusive franchise, the government shall grant operational rights to one non-governmental organization to provide designated products and services in a designated field. In the meantime, the government has to enhance its supervision on the public goods delivered or service price set by the organization. If adopting non-exclusive franchise, the government shall grant several non-governmental organizations the operational rights in a designated field.

4. Subsidy. It refers to that the government gives subsidies to non-governmental organizations in forms of allowance, preferable loan or tax reduction and exemption. This will allow qualified consumers to purchase designated goods that they couldn't afford from the producers with subsidies at a lower price. In this case, non-governmental organizations are the producer, and the government and consumers are the arrangers who pay to the producer.

5. Voucher. Voucher system refers to that the government grants coupons to individuals with legal qualifications to some designated service, relevant non-governmental organizations then earn these coupons through competition, which will later be exchanged by the government with currency. Therefore, individual choices can fuel service competition, lower supply cost through competition and improve service quality. The voucher system aims to whittle down private interest groups' (doctors, nursing homes, social service agencies, training professionals and lawyers) control on the public service decision-making power of the government and on consumers, directing the funds provided by the government to groups most in need instead of organizations who provide services. US and UK have set up successful examples of voucher system in areas of public school education, housing and healthcare reforms.

6. Free market. It is the most common form of service arrangement used to provide common personal belongings and chargeable goods. In this case, consumers arrange services and select producers, and non-governmental organizations are the producer. The government aims to institutionalize and standardize the market to protect the legitimate rights of various parties. As the most common form of service arrangement, free market is widely used to provide necessities and services such as food, clothes, water, electricity and houses.

7. Voluntary service. Non-governmental organizations like charities provide many services in need through voluntary activities. Other voluntary organizations also offer many community services, such as security patrol by neighborhood groups, fire protection by volunteer fire brigades, psychological treatment and helping out by social workers associations, primeval forests and Yangtze River protection by environmental protection groups such as Friends of Nature. In this case, non-governmental organizations serve as the service arranger who engages in the production directly through its employees or indirectly through engaging other parities.

In different forms of arrangements, the government, the private sector and consumers are playing different roles in the delivery of public service (see Table 2).

Table 2. Institutional arrangement of public service

\begin{tabular}{llll}
\hline Service form & Arranger & Producer & Who pays? \\
\hline Contract & Government & Non-governmental organization & Consumers \\
Exclusive franchise & Government & Non-governmental organization(Single) & Consumers \\
Non-exclusive franchise & Government & Non-governmental organizations(Multiple) & Consumers \\
Subsidy & Government \& consumers & Non-governmental organization & Government\&consumers \\
Voucher & Consumers & Non-governmental organization & Government\&consumers \\
Free market & Consumers & Non-governmental organization & Consumers \\
Voluntary service & Non-governmental organization & Non-governmental organization or other organizations & N/A \\
\hline
\end{tabular}

Theory and practice indicate that under the circumstances of incomplete government, market and society, an effective selection and coordination system should be set up. In addition, based on the principle of economical rationality and cost minimization, we need to try to find out a balance point among the government, market and non-governmental organizations, so as to establish a coexistence system to effectively provide public goods and realize public interests. 


\section{Conclusion}

There is a wide range of views among scholars on the relationship between the government and non-governmental organizations, which can be interpreted from the following three aspects: economic development, policy orientation and operation. From the point of economic development, the coexistence refers to that the government and non-governmental organizations cooperate with each other and share resources, which can not only lower financial burden of the government, but also help achieve the economic development goals and maximize the efficiency and efficacy by utilizing abundant resources in the private sector. From the point of policy orientation, the coexistence relationship covers various members and service scope. Both parties need to jointly discuss service content and scope, resource allocation, service delivery, etc. Non-governmental organizations not only provide services but also participate in decision-making. Both parties cooperate for the same interests, share risks and rights and try to establish a local community and network to achieve larger social interest. From the point of operation, the coexistence means the government and non-governmental organizations reach equality through communication and learning. To achieve equality, both sides need to 1) participate in the decision-making process. All relevant interest parties can participate in the decision-making process and have an opportunity to express their own views before the final decision is made by one party which may bring inequality; 2) share responsibilities. Where there is right, there is responsibility; 3 ) trust each other. It is very important for the coexistence. Mutual trust and good interaction are the basis of the coexistence; and 4) create an effective communication system to dismiss divergences and establish a good partnership. All in all, from the point of economic development, we can find that the coexistence means that both parties work together to provide better public services and output, and try to improve service efficiency and effects; from the point of policy orientation, we can learn that it is to jointly manage public affairs. Through the establishment of the coexistence mechanism, a mutually beneficial, complementary and dependent coexistence network centered on public interests will be created by effectively consolidating resources in the public and private sectors. From the point of operation, we realize that the coexistence depends on the establishment of a coordination system of joint participation, responsibility sharing, mutual trust and good communication, which will assist the government and non-governmental organizations in the formation of a relationship with good interaction and implementation.

\section{About the author}

Qiong Li, sociology professor at East China University of Science and Technology, and is also a visiting professor at Purdue University. Her main research direction is development sociology. She is the author of Government Management and Conflict Border and many other books. She has published over 20 articles, led projects such as National Social Science Fund, China Postdoctoral Science Foundation, key consulting and research of Shanghai Municipal People's Government policies, Shanghai philosophy and social planning, etc. Her book of Government Management and Border Conflicts - Analysis of Groups, Organizations and Systems in Social Conflict has won the third prize in publication category of the 9th Shanghai Philosophy and Social Sciences Outstanding Book in 2008 .

\section{References}

[1] The UK Voluntary Sector Almanac 2010, The State of the Sector, National Council for Voluntary Organizations, 2010

[2] James Coleman, Community Conflict, Glencoe, IL:Free Press, 1957.

[3] Edwards, B., and Foley, M.“Civil Society and Social Capital:A Primer.'In Beyond Tocqueville, Civil Society and the Social Capital Debate in Comparative Perspective, edited by Edwards, B., Foley, M.and Diani, M. Hanover, NH:University Press Of New England.2001.

[4] Keane, J.Democracy and Civil Society. London:Verso.1988.

[5] Laothamatas, A. Business Association and the New Political Economy Of Thailand: From Bureaucratic Policy to Liberal Corporation.Boulder:West view Press.1992.

[6] Stepan, A.The State and Society in Peru in Comparative Perspective.Princeton:Princeton University Press.1978.

[7] Salamon, L., and Anheier, H.Global Civil Society:Dimensions of the Nonprofit Sector.U.S.A:The Johns Hopkins University Maryland..1999.

[8] Schmitt P.“Still a Century of Corporatism." In The New Corporatism, edited by Fredrick,P.and Stritch T..Notre Dame:The University Of Notre Dama Press.1974.

[9] Skloot, E.2000."Evolution or Extinction:A Strategy for Nonprofits in the Marketplace." Nonprofit and Voluntary Sector Quarterly,vol.29, no.2, June, 2000.

[10] UNDP.Human Development Report 2005.NY:Oxford University Press.2005.

[11] United Nations. Indicators for Monitoring the Millennium Development Goals.NY: United Nations.2003. 